\title{
Penanganan Rheumatoid Arthritis dengan Model Comfort Food for the Soul pada Lanjut Usia di Panti Werdha Kota Jambi
}

\author{
Hesty \\ Program Studi DIII Keperawatan, STIKes Baiturrahim Jambi \\ Email:hestywiqi@gmail.com
}

Submitted : 10/12/2020

Accepted: 10/01/2022

Published: 28/01/2022

\begin{abstract}
The main complaint felt by patients with Rheumatoid Arthritis $(R A)$ is pain that is very disturbing, affecting daily activities and quality of life. RA pain felt by the elderly has an impact, including making sufferers feel uncomfortable, often afraid to move for fear of severity so that it reduces productivity, disrupts body balance so that it is at risk for falling, becomes dependent on others and causes stress to sufferers. Pain experienced by a person is complex and is the result of the interaction of physiological, psychological factors, as well as the individual's past experience, context, and the benefits of the therapy he has undergone so far. Patients' perceptions of the pain they feel can also affect their behavior and affective responses, so an effective strategy is needed to deal with pain, emotional distress, and psychosocial barriers experienced. One form of intervention in the comfort food model for the soul can be done with religious music therapy. One of the management of RA is through the comfort food for the soul model. This community service activity was carried out at the Tresna Werdha Budi Luhur Social Home located on Jalan Pangeran Hidayat Paal V Kota Baru Jambi City in July 2020. The service method used a survey, lecture, discussion and demonstration approach. The results achieved were health education about Rheumatoid Arthritis, making education media posters, and booklets. $95 \%$ of the elderly understand how to treat Rheumatoid Arthritis pain. Comfort Food for the Soul model, .90\% of moderate pain changes to mild pain.
\end{abstract}

Keywords: elderly, pain, rheumatoid arthtritis

\begin{abstract}
Abstrak
Keluhan utama yang dirasakan pada penderita Rheumatoid Arthritis (RA) adalah nyeri yang sangat mengganggu, mempengaruhi aktivitas harian dan kualitas hidup. Nyeri RA yang dirasakan lansia tersebut memberikan dampak di antaranya adalah membuat penderita merasa tidak nyaman, seringkali takut untuk bergerak karena takut terjadi keparahan sehingga menurunkan produktifitas, menggangu keseimbangan tubuh sehingga beresiko untuk jatuh, menjadi tergantung kepada orang lain dan menyebabkan stress pada penderitanya.Nyeri yang dialami seseorang bersifat kompleks dan merupakan hasil interaksi faktor-faktor fisiologis, psikologis, serta pengalaman masa lalu individu, konteks, dan manfaatterapi yang dijalaninya selamaini.Persepsi penderita terhadap nyeri yang dirasakan juga dapat mempengaruhi perilaku dan respon afektifnya sehingga diperlukan strategi yang efektif untuk mengatasi rasa nyeri, emotional distress, dan hambatan psikososial yang dialami.Salah satu bentuk intervensi dalam model kenyamanan makanan bagi jiwa dapat dilakukan dengan terapi musik religius.Salah satu penatalaksanaan RA adalah melalui model comfort food for the soul.Kegiatan pengabdian masyarakat ini dilaksanakan di Panti Sosial Tresna Werdha Budi Luhur yang terletak di Jalan Pangeran Hidayat Paal V Kota Baru Kota Jambi pada Bulan Juli 2020. Metode pengabdian menggunakan pendekatan survey, ceramah, diskusi dan demonstrasi. Hasil yang dicapai adalah penyuluhan kesehatan tentang Rheumatoid Arthritis, pembuatan KIE media poster, dan booklet. $95 \%$ lansia memahami bagaimana penanganan nyeri Rheumatoid Arthritis.Model Comfort Food for the Soul, .90\% terjadi perubahan nyeri sedang ke nyeri ringan.
\end{abstract}

Kata Kunci : lansia, nyeri, rheumatoid arthtritis 


\section{PENDAHULUAN}

Lanjut usia (lansia) adalah kelompok manusia yang berusia 60 tahun keatas, pada lanjut usia akan terjadi proses menghilangnya kemampuan jaringan untuk memperbaiki diri atau menganti dan mempertahankan fungsi normalnya secara perlahan-lahan sehingga tidak dapat bertahan terhadap infeksi dan memperbaiki kerusakan yang terjadi (Sunaryo, 2016). Lansia adalah suatu proses menghilangnya secara perlahanlahan kemampuan jaringan untuk memperbaiki diri atau menganti diet dan mempertahankan struktur dan fungsi normalnya sehingga tidak dapat bertahan terhadap jejas dan memperbaiki kerusakan yang diderita (Darmojo, 2015).Kualitas hidup lansia terutama status fungsionalnya perlu ditingkatkan sehingga lansia dapat melakukan ADL secara mandiri. Hidup sehat pada lansia adalah dambaan bagi setiap manusia dimana pada usia menginjak 60 tahun diharapkan tetap bisa beraktifitas, bersosialisasi, dan menjalankan rutinitas sehari - hari serta selalu tetap semangat menjalani masa lansia. Untuk itu harus membiasakan pola hidup sehat pada masa lansia (Fatmawati et al., 2019).

Gangguan persendian adalah satu keluhan yang sering di ungkapkan lansia dan menempati urutan ke dua, 14,5\% setelah penyakit kardiovaskuler dalam pola penyakit masyarakat usia >55 tahun (Kemenkes RI, 2013). Salah satu gangguan persendian adalah Rheumatoid Arthritis RA) yang merupakan penyakit kronis, sistemik secara khas berkembang perlahan-lahandan ditandai oleh adanya radang yang sering kambuh pada persendian (G.R.Falsarella, 2012).

Keluhan utama yangdirasakan pada penyakit ini adalah nyeri.Menurut sebagian besar lansia, nyerimerupakan keadaan yang sangatmengganggu, suatu masalah yang akanmempengaruhi aktivitas harian dan kualitas hidup (Papila 2009). Adanya nyeri RA yang dirasakan lansia tersebut akan memberikan dampak pentingterhadap fungsi tubuh sehari-hari atauimobilisasi dan psikologis, di antaranyaadalah adanya nyeri Rheumatoid Arthritismembuat penderita merasa tidak nyaman,seringkali takut untuk bergerak karena takutterjadi keparahan sehingga menurunkan produktifitas karena nyeri pada persendianbisa juga mengganggu keseimbangan tubuhtidak stabil sehingga beresiko untuk jatuh, terjadi ketergantungan kepadaorang lain dan dapat menyebabkan stresspada penderitanya (Purwoastuti, 2009).

Nyeri yang dialami seseorang bersifatkompleks dan merupakan hasil interaksifaktor-faktor fisiologis, psikologis, sertapengalaman masa lalu individu, konteks,dan manfaatterapi yang dijalaninya selamaini.Persepsi penderita terhadap nyeri yang dirasakan juga dapat mempengaruhi perilaku dan respon afektifnya (Dewi, 2009). Penderita yang mengalami stress akibat nyeri kronis dapat mengakibatkan intensitas nyeri yang dirasakan meningkat (Lumbantoruan, 2012). Tampak jelas bahwa berbagai faktor psikososial memiliki dampak yang besar terhadap penderita nyeri kronis sehingga diperlukan strategi yang efektif untuk mengatasi rasa nyeri,emotional distressdan hambatan psikososial yang dialami (Grant, 2005; Hayes2006; Godsoe, 2008; Morrison \& Bennet, 2009).Salah satu permasalahan lansia dalam sistem muskuloskeletal adalah Rheumatoid Arthritis (RA). Pada orang tua dengan RA memiliki keluhan utama nyeri yang juga dapat menjadi stressor terhadap stres.Salah satu bentuk intervensi dalam model kenyamanan makanan bagi jiwa dapat dilakukan dengan terapi musik religius.Salah satu penatalaksanaan RA adalah melalui model comfort food for the soul.

Panti Sosial Tresna Werdha terletak di Jl. Pangeran Hidayat No.75, Paal Lima, Kota Baru, Kota Jambi, memiliki kapasitas penghuni sebanyak 70 orang yang berasal dari daerah yang ada di Provinsi Jambi, bahkan ada yang dari luar Provinsi. Salah satu kegiatan yang dilakukan oleh panti werdha antara lain :1) Preventif yaitu: melaksanakan kegiatan olahraga seperti membersihkan lingkungan, jalan pagi dan 
senam lansia sekali seminggu; bersama puskesmas memeriksa kesehatan para lansia setiap hari kamis; mengatur dan membiasakan para lansia untuk dapat tidur beristirahat secukupnya, 2) Kuratif, seperti : pengobatan untuk para lansia yang mengalami sakit-sakit ringan,dapat diberikan pengobatan langsung dengan obat-obat ringan yang disediakan panti. Bagi lansia yang mengalami sakit dan memerlukan perawatan/ rawat inap akan dirujuk ke RSU provinsi setelah mendapat rekomendasi dari dokter/ Puskesmas. 3) Bimbingan mental dan spiritual : Untuk membiasakan lansia-lansia di UPTD PSTW melaksanakan ibadah sesuai dengan agama yang dianut,maka dilaksanakanlah kegiatan bimbingan mental spiritual, berupa ceramah-ceramah agama/ pengajian-pengajian bagi lansia.

Pengabdian masyarakat sebelumnya juga telah dilakukan dengan pemberian terapi jahe dan senam rematik(Fatmawati \& Ariyanto, 2020). Survei awal yang dilakukan di Panti Sosial Tresna Werdha Budi Luhur Provinsi Jambi ditemukan 4 orang lansia menderita RA, lansia mengatakan sering kambuh rasa nyeri pada sebagian sendi kaki dan tangan terutama malam dan pagi hari, para lansia tidak memahami model kenyamanan makanan bagi jiwa yang salah satunya dapat dilakukan dengan terapi musik religius untuk mengurangi nyeri sendi. Adapun data lansia PTSW berdasarkan 10 kasus penyakit terbanyak yang diderita sebagai berikut:

Tabel 1. Jumlah kasus penyakit lansia di panti Tresna Werdha Budi Luhur Provinsi Jambi

\begin{tabular}{clc}
\hline No & \multicolumn{1}{c}{ Penyakit } & Jumlah \\
\hline $\mathbf{1 .}$ & Rematik & 43 \\
$\mathbf{2 .}$ & Hipertensi & 23 \\
$\mathbf{3}$ & Stroke & 7 \\
$\mathbf{4}$ & Maag(gastritis) & 6 \\
$\mathbf{5}$ & Insomnia & 5 \\
$\mathbf{6}$ & Rematoid & 4 \\
& artritis & \\
$\mathbf{7}$ & Diabetes & 3 \\
& mellitus & \\
\hline
\end{tabular}

\begin{tabular}{cll}
$\mathbf{8}$ & Sesak napas & 2 \\
$\mathbf{9}$ & Asma & 2 \\
$\mathbf{1 0}$ & Asam urat & 2 \\
& (Gout athritis) \\
\hline & Sumber: (PSTW Budi Luhur, 2018)
\end{tabular}

Berdasarkan data diatas didapatkan Rheumatoid Arthritismenempati urutan ke-6 dari berbagai penyakit yang ada di Panti Tresna Werdha dengan jumlah penderita sebanyak 4 orang. Dari uraian diatas maka kami tertarik untuk melakukan kegiatan pengabdian masyarakat dengan judul Penanganan Rheumatoid Arthritis dengan model comfort food for the Soul pada lansia di Panti Sosial Tresna Werdha Kota Jambi.

\section{TARGETDAN LUARAN}

\section{A. Target}

Tabel 2. Target kegiatan

\begin{tabular}{|c|c|c|}
\hline No & Kegiatan & Target $(\%)$ \\
\hline 1 & $\begin{array}{l}\text { Melaksanakan } \\
\text { kegiatan } \\
\text { penyuluhan } \\
\text { kesehatan pada } \\
\text { lansia tentang } \\
\text { penangananRA } \\
\text { dengan model } \\
\text { comfort food for } \\
\text { the soul. }\end{array}$ & $\begin{array}{l}95 \% \text { Penderita } \\
\text { RA memahami } \\
\text { cara tentang } \\
\text { penangananRA } \\
\text { dengan model } \\
\text { comfort food for } \\
\text { the soul.. }\end{array}$ \\
\hline 2 & $\begin{array}{l}\text { Pembuatan } \\
\text { media } \\
\text { (poster) }\end{array}$ & 1 poster \\
\hline 3 & $\begin{array}{l}\text { Melaksanakan } \\
\text { pengkajian } \\
\text { tingkat stress. }\end{array}$ & $\begin{array}{lr}\text { Berjalan dengan } \\
\text { lancar di Panti } \\
\text { Sosial Tresna } \\
\text { Werdha } \\
\text { lansia dapat hadir } \\
\text { mengikuti } \\
\text { kegiatan }\end{array}$ \\
\hline 3 & $\begin{array}{l}\text { Melaksanakan } \\
\text { pengkajian skala } \\
\text { nyeri (pre dan } \\
\text { post test) }\end{array}$ & $\begin{array}{l}90 \% \text { terjadi } \\
\text { perubahan skala } \\
\text { nyeri dari sedang } \\
\text { menjadi ringan }\end{array}$ \\
\hline
\end{tabular}

\section{B. Luaran}

Adapun Luaran dalam kegiatan ini adalah:

1. Teridentifikasi masalah lansia mengenai nyeri Rheumatoid

Arthritis, 
meningkatnya pengetahuan lansia tentang penanganan nyeri Rheumatoid Arthritisdengan model comfort food for the soul

2. Terlaksananya kegiatan edukasi tentang penanganan nyeri Rheumatoid Arthritispada lansia di Panti Sosial Tresna Werdha Kota Jambi

3. Terlaksananya pemberian leaflet sebagai pendamping kegiatan dalam edukasi penanganan nyeri Rheumatoid Arthritisini.

4. Publikasi artikel pada jurnal pengabdian masyarakat (draft).

\section{METODE PELAKSANAAN}

Sasaran kegiatan pengabdian masyarakat ini adalah lansia penderita RA yang tinggal di Panti Werdha Budi Luhur Kota Jambi.Tujuan dari pengabdian masyarakat ini diharapkan setelah mengikuti sosialisasi (penyuluhan dan demonstrasi) terapi musik religi, lansia mampu memahami dan mendemonstrasikan kembali untuk mendengarkan musik religi. Adapun metode perencanaan pengabdian kepada masyarakat di Panti Sosial Tresna Werdha ini sesuai dengan rencana sebagai berikut :

1. Pertemuan dengan kepala Panti Sosial Tresna Werdha tentang rencana pengabdian kepada masyarakat.

2. Pertemuan dengan tim pelaksana lapangan untuk rencana tekhnis pelaksanaan pengabdian kepada masyarakat ini.

3. Pada tahap implementasi: sosialisasi dan edukasi tentang penanganan nyeri Rheumatoid Arthritisdengan model comfort food for the soul, tujuan, waktu pelaksanaan dan cara melakukannya.

4. Demonstrasi model comfort food for the soul(musik religi)

5. Pemberian media KIE (leaflet)

6. Metode selanjutnya adalah mengajak dan memotivasi lansiauntuk melaksanakan setiap waktu jika terjadi nyeri.
7. Diskusi dan tanya jawab mengenai permasalahan yang berkaitan denga masalah nyeriRheumatoid Arthritis.

8. Monitoring dan evaluasi kegiatan

\section{HASIL DAN PEMBAHASAN}

Kegiatan pengabdian masyarakat di Panti Sosial Tresna Werdha Budi Luhur Kota Jambi telah dilaksanakan sesuai dengan rencana yang telah disusun. Kegiatan ini dibantu oleh mahasiswa/i program studi D3 Keperawatan. Kegiatan penyuluhan ini bertujuan agar lansia dapat melakukan aktivitas sehari-hari tanpa merasa terganggu dengan nyeri yang dirasakan.

Tabel 3. Hasil pengukuran skala nyeri sebelum dan setelah dilakukan terapi mendengar musik religi

\begin{tabular}{cccc}
\hline $\begin{array}{c}\text { No } \\
\text { Responden }\end{array}$ & $\begin{array}{c}\text { Umur } \\
\text { (Th) }\end{array}$ & $\begin{array}{c}\text { Skala } \\
\text { Nyeri } \\
\text { Pre }\end{array}$ & $\begin{array}{c}\text { Skala } \\
\text { Nyeri Post }\end{array}$ \\
\hline $\mathbf{1}$ & 76 & 6 & 4 \\
$\mathbf{2}$ & 73 & 7 & 5 \\
$\mathbf{3}$ & 65 & 6 & 4 \\
$\mathbf{4}$ & 73 & 6 & 4 \\
\hline
\end{tabular}

Diperoleh hasil bahwa terdapat perubahan skala nyeri dari sedang menjadi ringan sebesar 80\%, skala nyeri berat menjadi sedang sebesar 20\% nyeri. Evaluasi dari program kegiatan pengabdian kepada masyarakat di Panti Sosial Tresna Werdha Budi Luhur Kota Jambi telah dilaksanakan dimulai dari persiapan /perencanaan, pelaksanaan/proses dan evaluasi hasil.

Pada akhir kegiatan luaran dari kegiatan pengabdian ini yaitu:

a. Publikasi artikel pada jurnal pengabdian masyarakat

b. Tersedianya media KIE (poster dan bookletefektif/ mudah dipahami dan diterapkan)

c. Dilaksanakannya penyuluhan tentang terapi musik religi, lansia mampu memahami dan mendemonstrasikan kembali untuk mendengarkan musik religi. Lansia memahami pengertian, penyebab, klasifikasi, tanda dan gejala, 
komplikasi, pencegahan dan penanganan Rheumatoid Arthritis.

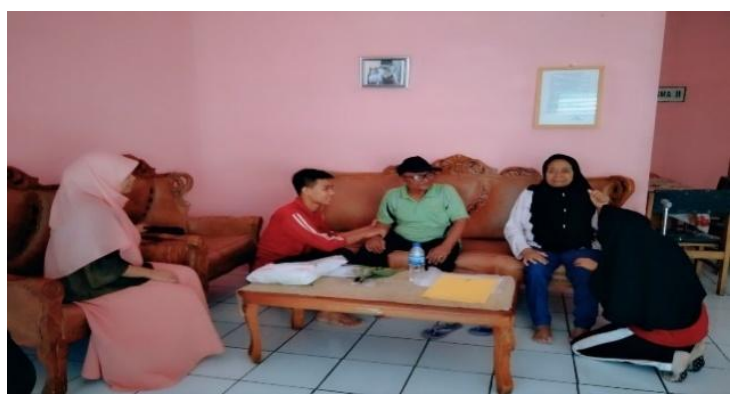

Gambar 1. Edukasi Rheumatoid Arthritis

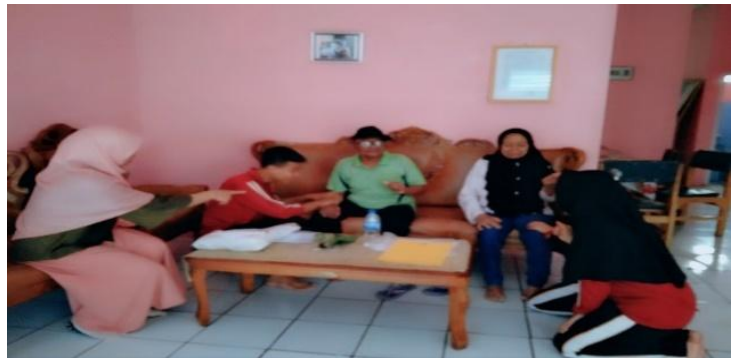

Gambar 2. Demonstrasi

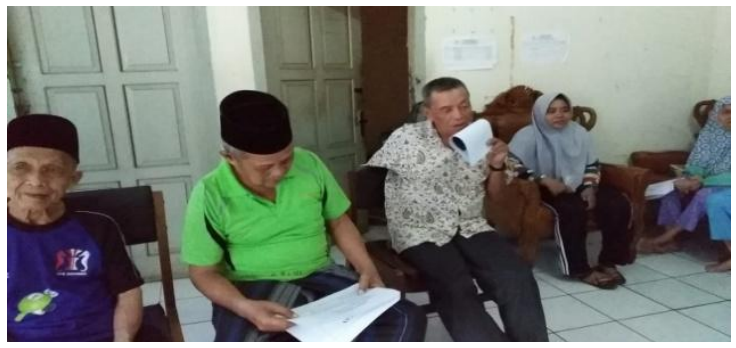

Gambar 3. Tanya jawab

\section{KESIMPULAN DAN SARAN}

\section{A. Kesimpulan}

1. Peserta penyuluhan yang terdiri dari lansia $95 \%$ dapat memahami pengertian, penyebab, klasifikasi, tanda dan gejala, komplikasi, pencegahan dan penanganan RA.

2. Peserta penyuluhan mampu melaksanakan secara mandiri penanganan nyeri yang dialami akibat RA.

3. Lansia $90 \%$ mengalami pengurangan nyeri sedang menjadi ringan.

\section{B. Saran}

Diharapkan kepada lansia setelah mendapatkan penyuluhan ini dapat melakukan secara rutin jika mengalami nyeri RA, untuk perawat dan tim kesehatan lebih optimal memantau, memotivasi serta meningkatkan kesehatan lansia yang mengalami nyeri sendi.

\section{UCAPAN TERIMAKASIH}

Termakasih kepada Ketua Sekolah Tinggi Ilmu Kesehatan Baiturrahim, Kepala Panti Sosial Tresna Werdha Kota Jambi dan staf yang telah mendukung dan memfasilitasi kegiatan pengabdian kepada masyarakat ini sehingga kegiatan ini dapat terwujud.

\section{DAFTAR PUSTAKA}

Badan Pusat Statistik., 2012. Penduduk Lanjut Usia Menurut Provinsi. Buletin Jendela Data dan Informasi Kesehatan. Kementrian Kesehatan RI.

Dewi D., 2009. Pengaruh Tehnik Relaksasi Nafas Dalam Terhadap Penurunan Persepsi Nyeri pada Lansia dengan Arthritis Reumathoid. Jurnal Keperawatan Soedirman (The Soedirman Journal of Nursing). Vol.4(2), pp.46-53.

Darmojo, B,R dan Martono, H., 2010. Buku Ajar Geriatri. Balai Penerbit FKUI: Jakarta.

Dalimartha, S., 2008. Herbal untuk Pengobatan Reumatik. Penebar Swadaya: Jakarta.

Depkes RI., 2010. Pedoman Umum Pengembangan Desa dan Kelurahan Siaga Aktif, Jakarta : Pusat Promosi Kesehatan Sekretaris Jendral Kementerian Kesehatan RI

Padila., 2003.Buku Ajar Keperawatan Gerontik. Nuha Medika: Yogyakarta.

Fatmawati, T. Y., \& Ariyanto, A. (2020). PKM Kelompok Lanjut Usia dalam Penatalaksanaan Rematik di Panti Sosial Tresna Werdha Budi Luhur. Jurnal Abdimas Kesehatan (JAK), 2(1), 76. https://doi.org/10.36565/jak.v2i1.99

Fatmawati, T. Y., Ariyanto, A., \& Nurfitriani, N. (2019). PKM Peningkatan Perilaku Hidup Sehat Pada Lanjut Usia Di Panti Sosial Tresna Werdha Kota Jambi. J-Dinamika: 
Jurnal Pengabdian Masyarakat, 4(1), 98-102. https://doi.org/10.25047/jdinamika.v4i1.1055

Wilmana, F,K., \& Gan, S., 2007. Analgesikantipiretik, analgesik-anti-inflamasi non steroid dan obat pengganti sendi lainnya.

Wang, C. F., Sun, Y. L., \& Zang, H. X., 2014. Music therapy improves sleep quality in acute and chronic sleep disorders: A meta-analysis of 10randomized studies. International journal of nursing studies. Vol 51(1), pp.51-62. 